\title{
Iron isotope compositions of ultrapotassic volcanic rocks from northeastern China and the implication on deep oxygen cycle
}

\author{
YongSheng HE*, QIANQIAN YAN, SHAN Ke
}

State Key Laboratory of Geological Processes and Mineral Resources, China University of Geosciences, Beijing 100083, China.

* corresponding author: heys@cugb.edu.cn

Cycling of multiple valent elements in subduction zones could have had great impact on the oxidising potential of the Earth's surface. Iron, as the most abundant one, may have played a key role in these cycles. Its isotopes fractionate during preferential separation of $\mathrm{Fe}^{3+}, \mathrm{Fe}^{2+}$ and $\mathrm{Fe}^{0}$ among geological reservoirs, and thus can be a potential tracer for such cycles. A pathway driven by deep carbon cycle has been recently proposed based on iron isotope evidence of Cenozoic basalts in eastern China ${ }^{[1]}$. This pathway releases oxidising basalts characterized by heavy iron isotope compositions at cost of burying surface carbonates at deep mantle (likely $>250 \mathrm{~km}$ ) as diamond, with net oxidising potential back to the surface. To investigate whether this pathway may occur at shallower cycles, here we report iron isotope data of 17 ultrapotassic volcanic rocks from Xiaogulihe, northeastern China. These samples are characterized by $\delta^{26} \mathrm{Mg}$ down to $-0.61 \%$, and most likely were derived from lithospheric mantle metasomatized by agents from carbonated eclogites. The results show that they have homogeneous $\delta^{56} \mathrm{Fe}$ with an average of $0.132 \pm 0.023 \%$ (2SD), within the range of global MORB $(\sim 0.105 \pm 0.045 \%$ ) [2] but substantially lower than that (up to $0.29 \%$ ) of contemporaneous sodium-rich basalts from eastern China at a given $\delta^{26} \mathrm{Mg}{ }^{[1]}$. Correlations with ${ }^{87} \mathrm{Sr} /{ }^{86} \mathrm{Sr},{ }^{176} \mathrm{Hf} /{ }^{177} \mathrm{Hf}$ and $\delta^{26} \mathrm{Mg}$ indicate the slightly higher $\delta^{56} \mathrm{Fe}$ of Xiaogulihe samples relative to mean MORB can be attributed to addition of recycled carbonated eclogites in the mantle sources. Such metasomatism, however, had not significantly enhanced iron isotope fractionation during later partial melting that produced the ultrapotassic basalts. $\mathrm{Fe}^{3+} / \sum \mathrm{Fe}$ of the mantle sources for Xiaogulihe samples could have not been substantially increased during metasomatism by agents from carbonated eclogites. This study thus confirms that the Cdriven pathway may not operate at lithospheric depths, where $\mathrm{Fe}^{0}$ is not saturated to cause reduction of carbonates at supersolidus conditions ${ }^{[3]}$.

[1] He et al., 2019, EPSL; [2] Teng et al., 2013, GCA; [3] Rohrbach and Schmidt, 2011, Nature; [4] Samples measured are kindly provided by Dr. Yang Sun and Dr. Ji-Feng Yin. 